\title{
AN ISOMETRIC NORMATIVE DATABASE TO FACILITATE RESTORATION OF FUNCTION IN KNEE-INJURED ACTIVE YOUNG ADULTS
}

\section{Professor J Charteris}

\begin{abstract}
Prohibitive costs technologically advanced dynamometers need not dissuade rehabilitationists from making useful assessments of musculo-skeletal performance in clinical settings. The use of simple strain-gauge measures of isometric torque is demonstrated using knee flexor-extensor capacities, dominance ratios, contralateral asymmetries and sexual dimorphism ratios. Functional restoration of knee-injured active young adults, using normative charts as a data base, is a cheap and feasible option.
\end{abstract}

\section{INTRODUCTION}

Few physiotherapists in South Africa can afford the expense of sophisticated isokinetic dynamometers for measuring muscular strength increments during rehabilitation, or the time to interpret the subtleties of muscle dynamics revealed by these technologies. The reality of the situation, for the vast majority of patients able to get physiotherapy at all, is that subjective clinical assessments most often determine rehabilitation steps and the termination of services to the client. At best, simple though effective isometric or isotonic testing guide these clinical judgements. For the foreseeable future in South Africa, we are facing increasing demands for medical and allied medical services, with decreasing expectation of expensive, state-ofthe-art technological support. This need not necessarity be viewed with dismay. recent evidence increasingly supports the view that the older, simpler, methods of gaining (and assessing) strength, when implemented with expertise, may be as effective as more sophisticated methods 1 .

\section{METHODS}

Thirty-five males and 35 females with no history of knee injury were selected from a group of normal active young adults. While seated, the subjects were requested to make maximal isometric efforts of knee extension and flexion against a wall-mounted steel cable, chain-linked to a precision strain-gauge (MIE system ${ }^{* *}$ ) coupled to a micro-processor.

The subject is braced in a seated position over a plinth, the knee flexed 90E. Maximal isometric extensions (or flexions) are made in this position, putting tension on a steel cable via a suitably padded strap around the leg. Movement is impossible but muscular efforts put tension on the cable and the interfaced strain gauge reads the force produced. Since this force will vary depending on the leverage involved the perpendicular distance from the knee joint centre to the cable is carefully measured and captured on the computer. Thereafter the product of force generated and lever-arm distance is computed automatically to yield torque curves for extension and flexion. For present purposes only maximal torques generated were of interest (See Table I).

At the same time subjects were asked to identify their "dominant" lower extremity, in order to test their perception of "dominance" against actually measured "dominance".

For this study "dominant" was defined as the isometrically determined stronger, and "non-dominant" as the contralateral weaker limb in terms of knee extensor and flexor capability.

\section{RESULTS}

Neither sex showed significant isometric torque differences between right and left limbs, for either extensors or flexors. Despite there being a dominant limb in terms of strength in each individual case, sufficient left-dominant individuals were present to obliterate a left-right difference. Thus left-right differences were within $2 \%$, for both sexes and for extensor and flexor torques. However, when absolute strength dominance (irrespective or left-right relationship) was measured, the differences were significant (Table I). Males and females responded very similarly in respect of these levels of difference, suggesting that there is no sex-related factor in contralateral $(\mathrm{Q} / \mathrm{Q} ; \mathrm{H} / \mathrm{H})$ asymmetry ratios. This is depicted in Figure 1.

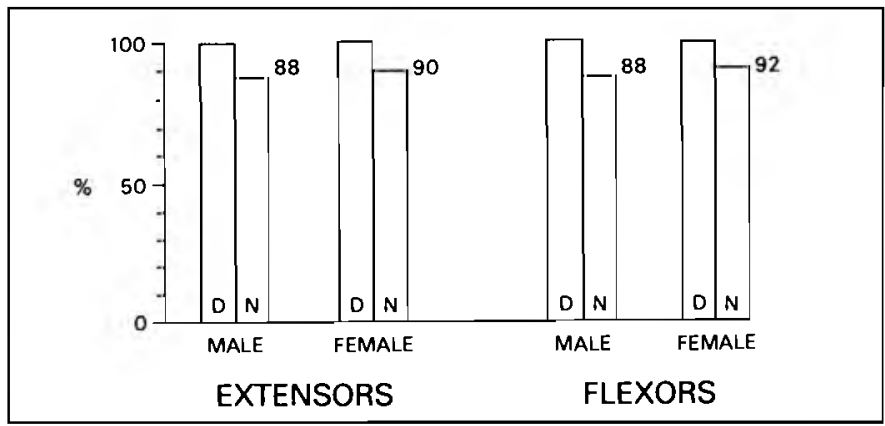

FIGURE 1: Dominant/Non-Dominant Ratios for seated isometric knee extensor and flexor torques.

In respect of knee isometric strength in the test position ( $90^{\circ}$ hip and knee flexion; seated), the less-strong (non-dominant) extensor ( $x 242 ; \pm 62 \mathrm{Nm}$ ) produced tension at $88 \%$ of that of the stronger (dominant) extensor (x 275; $\pm 68 \mathrm{Nm}$ ) in the case of the males. There was marginally less contralateral asymmetry in the females, the level being $90 \%$. Participation in one-sided activities may account for much of the asymmetry of tension development routinely shown in the results of strength testing on large numbers ${ }^{2}$.

Similarly, when the non-dominant flexor mean was compared with the dominant, the asymmetry level was about $91 \%$ for both sexes. These data suggest that, regardless of sex or the muscle group under investigation, isometric contralateral asymmetries (non-dominant: dominant) are close to $90 \%$ under these conditions (Table I).

In all cases there were significant differences between measured (MDR) and perceived (PDR) contralateral dominance ratios, and between MDR and right/left (RL) ratios, but not between PDR and $R L$ ratios (see Table I). In other words, since most subjects perceived their right limbs to be stronger, PDR and RL were the same. However, the limb perceived to be dominant was (in terms of isometric torque generated) actually weaker in a sufficient number of cases for there to be no congruence between PDR and MDR. The implication of the significant difference between PDR and MDR is that reliance should not be placed on patient's reports of dominance in cases where the therapist is attempting to find out whether an injured knee is the normally stronger or weaker of the two joints.

Under any test conditions normal subjects have stronger knee extensor than flexor mechanisms. This is borne out in the extensor (Q) to flexor $(\mathrm{H})$, or ipsilateral quadriceps-to-hamstring ratios (Table II). These ratios are movement-speed specific ${ }^{7,8}$, but under the isometric conditions imposed here the combined-limb $\mathrm{Q} / \mathrm{H}$ ratio

\footnotetext{
* Rehabilitation Research Unit, Department of Human Movement Studies, Rhodes University

** MIE Medical Research Limited, 6 Worthey Moor Road, Leeds
} 
TABLE I: SEATED ISOMETRIC TORQUES (Nm) OF KNEE EXTENSORS AND FLEXORS

\begin{tabular}{|c|c|c|c|c|c|c|c|}
\hline \multirow{3}{*}{$\vdots$} & \multicolumn{7}{|c|}{ QUADRICEPS (Q) } \\
\hline & \multirow{2}{*}{$\begin{array}{l}\text { Dominant } \\
(\mathrm{Nm})\end{array}$} & \multirow{2}{*}{$\begin{array}{c}\text { Non- } \\
\text { Dominant } \\
(\mathrm{Nm})\end{array}$} & \multirow{2}{*}{$\begin{array}{l}\text { Right } \\
(\mathrm{Nm})\end{array}$} & \multirow{2}{*}{$\begin{array}{l}\text { Left } \\
(\mathrm{Nm})\end{array}$} & \multicolumn{3}{|c|}{$\begin{array}{c}\text { CONTRALATERAL DOMINANCE RATIOS } \\
Q / Q\end{array}$} \\
\hline & & & & & $\begin{array}{l}\text { Measured } \\
(\text { MDR })\end{array}$ & $\begin{array}{l}\text { Perceived } \\
\text { (PDR) }\end{array}$ & $\begin{array}{c}\text { Right/Left } \\
\text { (RL) }\end{array}$ \\
\hline Male & $275(68)$ & 242 (62) & $\begin{array}{c}\Gamma--- \\
257(72)\end{array}$ & $260(63)$ & $\begin{array}{l}1.14(0.11) \\
{[88 \%]}\end{array}$ & $\begin{array}{c}r^{1.00}(0.16) \\
{[100 \%]}\end{array}$ & $\begin{array}{c}-7 \\
1.00(0.16) \\
{[1018]}\end{array}$ \\
\hline Female & $130(21)$ & 117 (21) & $122^{r---}$ & $\begin{array}{l}--7 \\
124(21)\end{array}$ & $\begin{array}{l}1.11(0.12) \\
{[90 \%]}\end{array}$ & $\begin{array}{c}0.98(0.15) \\
{[102 \%]}\end{array}$ & $\begin{array}{l}--7 \\
0.98(0.14) \\
{[1028]}\end{array}$ \\
\hline
\end{tabular}

\begin{tabular}{|c|c|c|c|c|c|c|c|}
\hline \multirow[t]{3}{*}{$\cdot$} & \multicolumn{7}{|c|}{ HAMSTRINGS } \\
\hline & \multirow{2}{*}{$\begin{array}{l}\text { Dominant } \\
(\mathrm{Nm})\end{array}$} & \multirow{2}{*}{$\begin{array}{c}\text { Non- } \\
\text { Dominant } \\
(\mathrm{Nm})\end{array}$} & \multirow{2}{*}{$\underset{(\mathrm{Nm})}{\text { Right }}$} & \multirow{2}{*}{$\begin{array}{l}\text { Left } \\
(\mathrm{Nm})\end{array}$} & \multicolumn{3}{|c|}{$\begin{array}{c}\text { DOMINANCE RATIOS } \\
\mathrm{H} / \mathrm{H}\end{array}$} \\
\hline & & & & & $\begin{array}{l}\text { Measured } \\
\text { (MDR) }\end{array}$ & $\begin{array}{l}\text { Perceived } \\
\text { (PDR) }\end{array}$ & $\begin{array}{l}\text { Right/Left } \\
\text { (RL) }\end{array}$ \\
\hline Male & $152(38)$ & $134(34)$ & $\begin{array}{c}\Gamma-\cdots \\
145(36)\end{array}$ & $\begin{array}{l}--7 \\
142(36)\end{array}$ & $\begin{array}{l}1.13(0.06) \\
{[888]}\end{array}$ & $\begin{array}{c}.04(0.09) \\
{[968]}\end{array}$ & $\begin{array}{c}-\overline{1.02(0.09)} \\
{[988]}\end{array}$ \\
\hline Female & $72(12)$ & 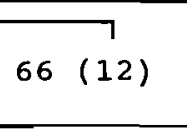 & $\begin{array}{c}r--- \\
70(12)\end{array}$ & $\begin{array}{l}--7 \\
69(11)\end{array}$ & $\begin{array}{c}1.09(0.07) \\
{[928]}\end{array}$ & $\begin{array}{c}\overline{1.00(0.10)} \\
{[1008]}\end{array}$ & $\begin{array}{c}--7 \\
1.01(0.10) \\
{[998]}\end{array}$ \\
\hline
\end{tabular}

NOTE: Solid link (- ) denotes significant differences $(\mathrm{p}<0.05)$

Broken-link (----) indicates no significant difference

Standard Deviations in parentheses.

Reciprocal of ratio, $(\%)$, in square brackets.

(both sexes) was 1.78 . Taking the reciprocal, this means that hamstrings were $56 \%$ as strong, isometrically, as quadriceps, which is in very close agreement with values reported in recent literature ${ }^{7,8}$. While knowledge of normal $\mathrm{Q} / \mathrm{H}$ ratios is critical for therapy to be meaningfully applied, misunderstanding of the ratio is common, and potentially harmful, (see discussion). In the present study useful data on agonist/antagonist ratios were revealed which, if used correctly, are of real clinical significance. Figure 2 shows that, regardless of sex or dominance or limb side, the flexor/extensor torques were insignificantly spread around 0.56 .

\begin{tabular}{|c|c|c|c|c|c|}
\hline & Dominant & Mon-Doninant & Right & Left & $\begin{array}{l}\text { LIKBS } \\
\text { COMBTNED }\end{array}$ \\
\hline Ma1es & $\begin{array}{l}1.85 \\
{[548]}\end{array}$ & $\begin{array}{l}1.75 \\
{[578]}\end{array}$ & $\begin{array}{l}1.77 \\
{[568]}\end{array}$ & $\begin{array}{l}1.83 \\
{[558]}\end{array}$ & $\begin{array}{l}1.78 \\
{[56 \%]}\end{array}$ \\
\hline remales & $\begin{array}{l}1.81 \\
{[558]}\end{array}$ & $\begin{array}{l}1.75 \\
{[578]}\end{array}$ & $\begin{array}{l}1.74 \\
{[578]}\end{array}$ & $\begin{array}{l}1.80 \\
{[568]}\end{array}$ & $\begin{array}{l}1.78 \\
{[568]}\end{array}$ \\
\hline
\end{tabular}

NOTE: Reciprocal of ratio, (1.e. H/Q ratio) as 8 , in square brackete.

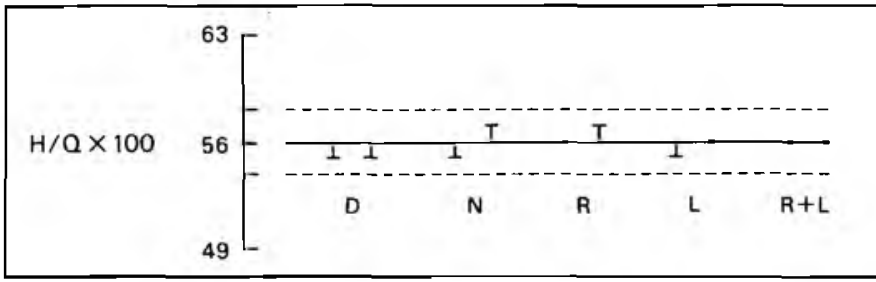

FIGURE 2: Deviation of mean values in H/Q Ratios Dominant (D); non-dominant (N); right $(\mathrm{F})$; left $(L)$ and combined ight and left $(R+L)$ floxor-to-extensor ratios, about the overall mean value of 56 . Left-most value in each pair is male; ight value in each pair is female
Sexual dimorphism in strength expression is revealed in these results (Table III). Again the picture was consistent, whether comparing extensors or flexors of either dominant or non-dominant limbs: the females were, effectively, $48 \%$ as strong as the males under these test conditions. Figure 3 shows how small the band of variability is around this sex-based differences.

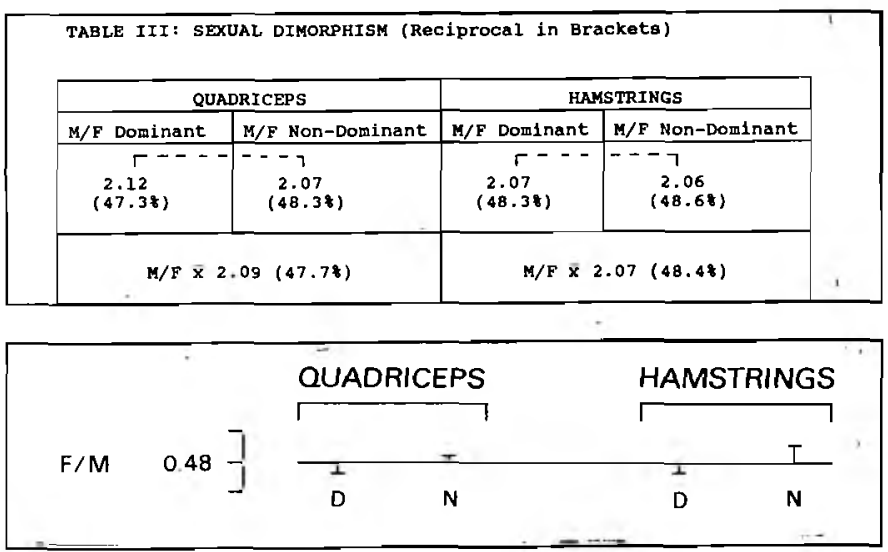

FIGURE 3: Deviation of mean values in Sexual Dimorphism of isometric torque.

Mean female/male (F/M) ratio is depicted as a horizontal band. Vertical bars show domi namt (D) and non-dominant (N) mean deviations for quadriceps and hamstrings. Clearly these are insignificantly spread about the overal F/M mean of 0.48 in the case of nor$\mathrm{mal}$ active young adults under these test conditions.

A 6-sigma table of Standard Scores was constructed from the dominant and non-dominant mean and standard deviation data, for extensors and flexors of the knee and for both sexes. This provides (Table IV) a useful guide to therapists concerned in increasing strength while ensuring normal agonist/antagonist ratios and remaining within acceptable contralateral asymmetry levels. 


\section{LICENSED BY THE DIRECTOR GENERAL OF RADIATION CONTROL}

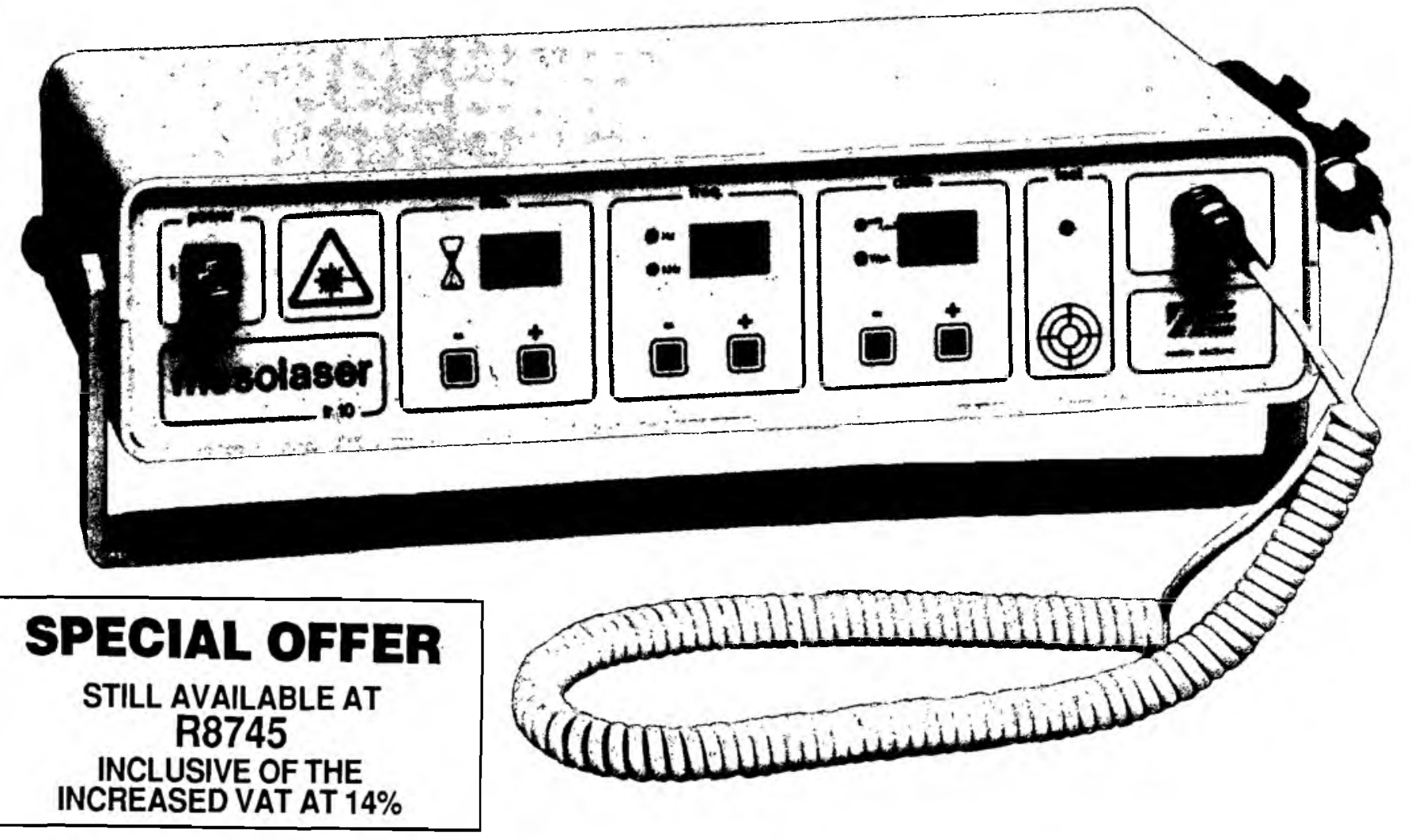

- A powerful portable Ga As infra-red laser, which uses the most up to date microcomputer technology

- The wave-length of $904 \mathrm{~nm}$ guarantees an optimal penetration depth.

- Variable peak power from 0 to 30 Watt in steps of 1 Watt.

- Capable of changing the frequency from $1 \mathrm{~Hz}$ to $5000 \mathrm{~Hz}$.

- Tip-touch sensor system for activating the laser beam.

- Measurement of the infra-red radiation using an optical sensor.

- Time clock which works only when the laser beam is activated.

- Safety glasses designed for laser therapy, consisting of interference filters. These keep the visual spectrum at $95 \%$ of normal.

- Unit built to comply with the international safety regulations IEC 601.

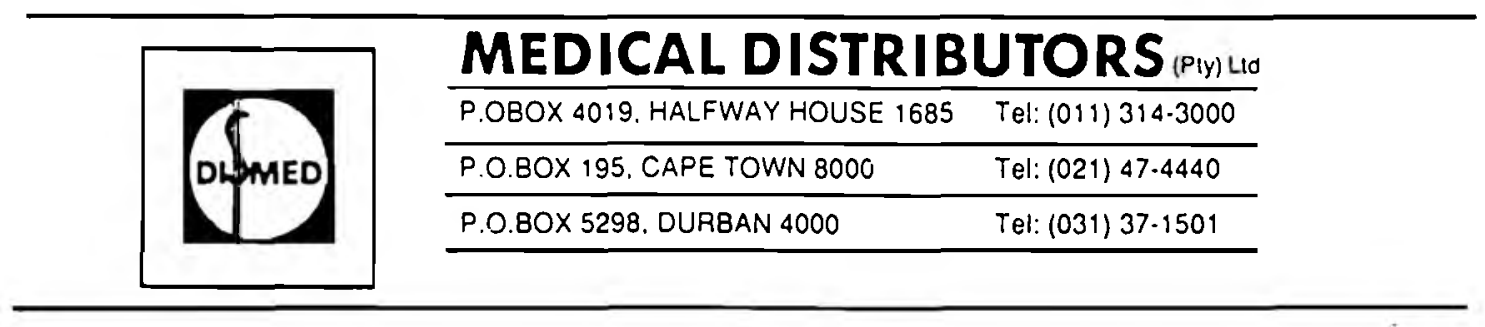




\begin{tabular}{|c|c|c|c|c|c|c|c|c|c|}
\hline \multirow{4}{*}{$\begin{array}{l}\text { ASSIGNED } \\
\text { RATING }\end{array}$} & \multirow{4}{*}{$\begin{array}{l}\text { STANDARD } \\
\text { SCORE }\end{array}$} & \multicolumn{8}{|c|}{ ISOYETRIC MAXIMUM TORQUE (NA) } \\
\hline & & \multicolumn{4}{|c|}{ MALES } & \multicolumn{4}{|c|}{ FEMALES } \\
\hline & & \multicolumn{2}{|c|}{ EXTENSOR } & \multicolumn{2}{|c|}{ FLEXOR } & \multicolumn{2}{|c|}{ EXTENSOR } & \multicolumn{2}{|c|}{ FLEXOR } \\
\hline & & DoM & N/D & DOM & N/D & DOM & $\mathrm{N} / \mathrm{D}$ & DOM & N/D \\
\hline \multirow{6}{*}{ EXCELLENT } & 100 & 480 & 427 & 266 & 236 & 195 & 182 & 108 & 103 \\
\hline & 95 & 459 & 408 & 255 & 226 & 189 & 176 & 104 & 99 \\
\hline & 90 & 439 & 390 & 243 & 216 & 182 & 169 & 101 & 96 \\
\hline & 85 & 418 & 371 & 232 & 205 & 176 & 163 & 97 & 92 \\
\hline & 80 & 398 & 353 & 220 & 195 & 169 & 156 & 94 & 89 \\
\hline & 75 & 377 & 334 & 209 & 185 & 163 & 150 & 90 & 85 \\
\hline \multirow[t]{4}{*}{ GOOD } & 70 & 357 & 316 & 198 & 175 & 156 & 143 & 86 & 81 \\
\hline & 65 & 336 & 297 & 186 & 165 & 150 & 137 & 83 & 78 \\
\hline & 60 & 316 & 279 & 175 & 154 & 143 & 130 & 79 & 74 \\
\hline & 55 & 295 & 260 & 163 & 144 & 137 & 124 & 76 & 71 \\
\hline \multirow[t]{4}{*}{ AVERAGE } & 50 & 275 & 242 & 152 & 134 & 130 & 117 & 72 & 66 \\
\hline & 45 & 254 & 223 & 141 & 124 & 124 & 111 & 68 & 63 \\
\hline & 40 & 234 & 205 & 129 & 114 & 117 & 104 & 65 & 60 \\
\hline & 35 & 213 & 186 & 118 & 103 & 111 & 98 & 61 & 56 \\
\hline \multirow[t]{4}{*}{ POOR } & 30 & 193 & 168 & 106 & 93 & 104 & 91 & 58 & 53 \\
\hline & 25 & 172 & 149 & 95 & 83 & 98 & 85 & 54 & 49 \\
\hline & 20 & 152 & 131 & 84 & 73 & 91 & 78 & 50 & 45 \\
\hline & 15 & 131 & 112 & 72 & 63 & 85 & .72 & 47 & 42 \\
\hline \multirow[t]{3}{*}{ DEFICIENT } & 10 & 111 & 94 & 61 & 52 & 78 & 65 & 43 & 38 \\
\hline & 5 & 90 & 75 & 49 & 42 & 72 & 59 & 40 & 35 \\
\hline & 0 & 70 & 57 & 38 & 32 & 65 & 52 & 36 & 31 \\
\hline
\end{tabular}

In using this scale it is important to keep in mind the sample upon which it was based, viz. normal, healthy young adults without history of knee injury. Thus certain patients may be so weak as not to be recordable on the standard score table. The concern of the present paper, however, is with restoration of normal knee function at a stage when the client is ready to benefit from an active-resistive exercise regimen.

\section{DISCUSSION}

It is sometimes implied that a particular H/Q ratio is advantageous for or required by, a particular activity: e.g., that; "long distance runners need a hamstring-to-quadriceps ratio of $0.60,3$.

Several authors have found, in specific instances, a ratio of 0.60 for hamstring-to-quadriceps torque as Nunn and Mayhew (1988) 1 suggest, but others have found ranges of variability between 0.43 and 0.90 for the same ipsilateral muscle imbalance between hamstring and quadriceps ${ }^{4}$. In fact there is no fixed agonist/antagonist knee ratio for humans, or specific groups, or even individuals: the hamstring-to-quadriceps (H/Q) ratio is an arithmetic calculation done on situation-specific data obtained in diverse ways and it varies with sex. age, state of training, body position, and velocity of motion. $5,6,7,8,9$ The ubiquitous force-velocity relationship applies, such that the $H / Q$ ratio increases as velocity increases because, while both extensor and flexor torques drop with speed increments, that of the quadriceps drops at a faster rate ${ }^{5,6,7}$. Worrell and co-workers $(1990)^{8}$ demonstrated sex-based differences in this ratio and lower $\mathrm{H} / \mathrm{Q}$ values when supine than when seated, probably because of a robbed length-tension relationship of the hamstrings in the supine position.

The present results are specific to seated $90 \mathrm{E}$ flexion isometric knee torques. It is fundamentally naive to fix torque values, bilateral asymmetries, agonist/antagonist ratios and sexual dimorphism indices, determined by any single technique, as if these were situationexclusive. For instance, claims that H/Q ratios "are", or "should be" some value which can be rote-learned and applied in all situations are invalid: the normal $\mathrm{H} / \mathrm{Q}$ ratio is a value that alters within each individual when tested isometrically versus isokinetically (where it is clearly a speed-dependent relationship).

The findings of the present study must be seen in this context: they are generalisable with caution, being relative to active young adults tested isometrically in the same seated position. Used as guidelines by the discerning therapist they should be useful in planning the on-going course of rehabilitation or of asymmetry reduction in otherwise unimpaired young adults who aspire to active lifestyles without undue risk of injury/re-injury of the knees.

\section{CLINICAL APPLICATION}

In respect of the normative data presented in Tables I to IV the question arises whether subjects with a history of knee impairment would be easily identified by their residual weaknesses and muscular imbalances, and whether the identified deficiencies provide guidelines as to what could be done to restore optimal function. Four case histories are presented to indicate the extent of weakness or imbalance, and to suggest a plan of action for restoration of normal levels of performance.

It is clearly not the purpose of this paper to prescribe any particular rehabilitation protocol to be followed. The present concern is whether simple seated isometric test results, in the form presented, can provide sufficient feedback to enable the therapist to achieve requisite strength increments and symmetries in knee-injured active young adults.

\section{Case Number One}

Subject TB (Female): Femoral Fracture (R), 12 months previously.

\section{Presenting Asymmetries}

This subject exhibits an essentially normal seated isometric $H / Q$ ratio of $\mathbf{0 . 6 3}$ on the surgically-treated (right) side but not on the unaffected (left) side. This apparent anomaly is due to the fact that the extensors and the flexors on the impaired side have lost strength concomitantly, without the ratio being shifted outside normal limits (Figure 4).

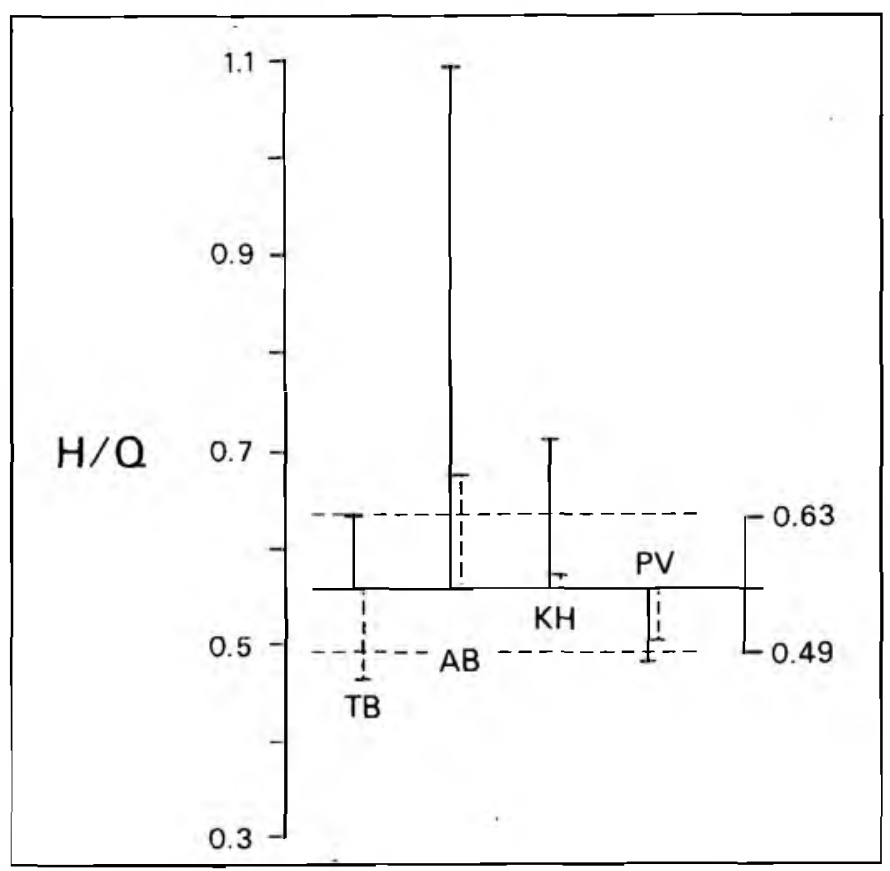

FIGURE 4: Clinically significant deviations in seated isometric $H / Q$ ratios.

Normal mean H/O ratio is 0.56 ( \pm 0.07 ) as depicted by horizontal band. Solld vertical bers depict aberrent right $\mathrm{H} / \mathrm{O}$ ratios; broken vertical bars show left H/O ratios of the same subjects.

The H:Q ratio on the unaffected (left) side, however, is 0.46 , which is more than one SD below the mean and is due to a left hamstring torque of $60 \mathrm{Nm}$ which is "poor" for a dominant limb. One might conjecture that postural and locomotor strategies adopted to move about with a surgically repaired right limb may have involved extensions on the unaffected side which kept the extensors relatively 


\section{PHYSICAL AND OCCUPATIONAL THERAPISTS}

\section{Hundreds of positions available immediately, in any state - Florida, Texas, New England
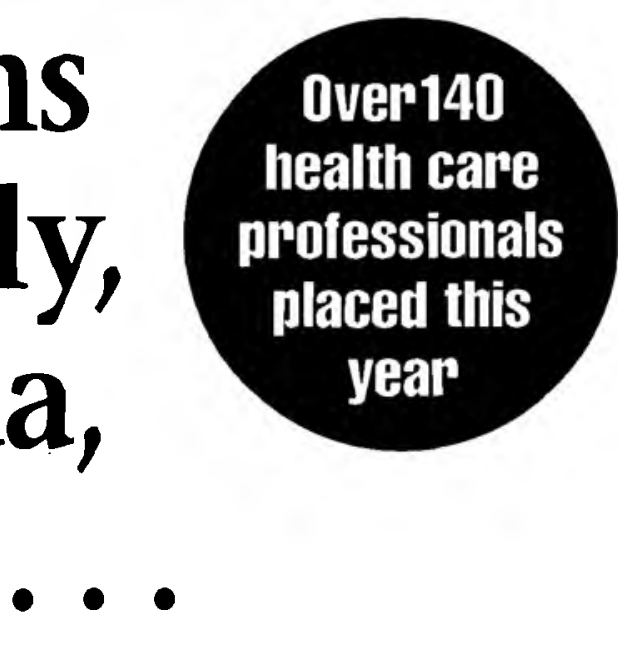

"When I called Medical Resources International, I got a job immediately - within two days. I couldn't believe it. Especially since I had waited several months for another agency to place me." - Josee Simard

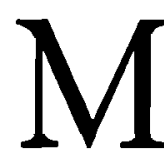

edical Resources International can place you in any specialty in any part of the United States - at $\$ 35,000$ to $\$ 60,000$ a year. And you get services no other company provides. Your licensure and credentialing fees are fully paid. Plus, we provide a FREE study course and materials to help you pass the state board exams.

We hire in all specialties, including:

- Clinical Coordinators and staff positions

- Outpatient orthopedics/Sports medicine

- Rehab, including neuro, cardiac, and brain injury

- Acute care

- Pediatrics
Work hardening
Geriatrics

See the U.S. - Apply for one of our traveling positions:

- Work in a variety of locations

- Company car

- Housing subsidy

"Medical Resources International handled all the details in assisting me in obtaining a clinical coordinator position in an out patient orthopedic practice in Florida. There was excellent communication before and after I accepted the job. All Medical Resources promises were met in a professional way." -Kerry D'Ambrogio

Full fee reimbursement for: - licensing - accreditation

\section{Other services:}

- FREE Air fare

- Medical, life, and professional insurance

- Housing assistance

\section{Medical Resources International-More Jobs, Better Service}

Medical Resources International represents more employers than any other agency. You receive the most opportunities and the best service. Call our toll-free number today for a FREE booklet that tells you what you need to know before coming to the U.S. and outlines the steps you need to take.

"The exciting challenge of working in the USA became a reality with the assistance of Medical Resources International. I made initial inquiries with several agencies, but quickly became impressed with the Medical Resources efficiency and personal approach. I am now working in Boston, thanks to Medical Resources."-Sue Williams

\section{Medical Resources International 209 S. Main St. Fairfield, IA 52556 U.S.A. — Fax (515) 472-1897}


well conditioned while the hamstrings underwent some degree of disuse atrophy. Be that as it may, the sub-optimal $H: Q$ ratio in this particular case does not point to the injured limb but rather to the contralateral side, suggesting that neither absolute torque values alone or agonist/antagonist ratios alone can be relied on to give the clinical picture: a general functional overview is necessary.

However, the contralateral $\mathrm{Q}: \mathrm{Q}$ and $\mathrm{H}: \mathrm{H}$ ratios are very revealing. The normal $Q: Q$ ratio is located between 0.85 and 1.15 with a mean essentially 1.00 . Similarly the normal $\mathrm{H}: \mathrm{H}$ ratio is somewhere between 0.97 and 1.13. Figure 5 shows that subject TB has a Q:Q ratio of 1.85 (left-dominant) which indicates the extent to which the deficient right knee extensors need to be rehabilitated to reduce bilateral asymmetry. This subject also exhibits an $\mathrm{H}: \mathrm{H}$ ratio of 1.33 (left-dominant) indicating the extent to which the right knee flexors need strengthening.

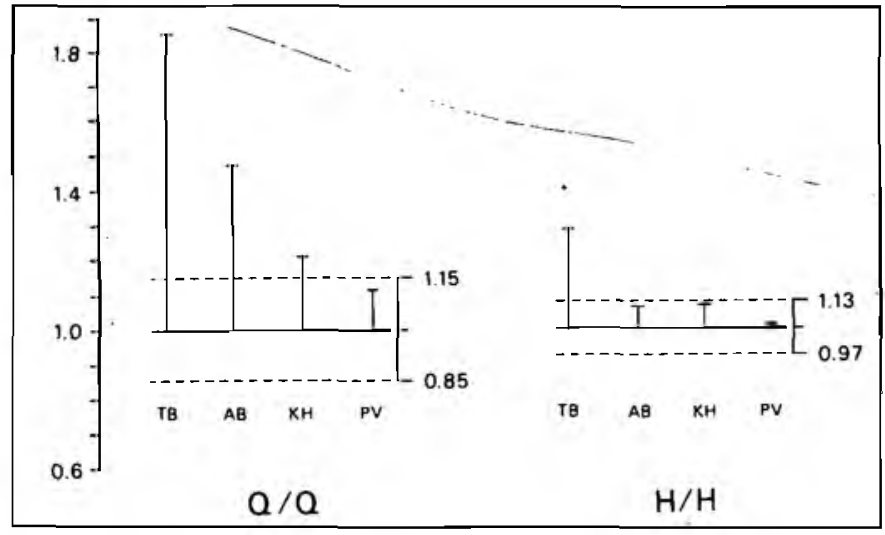

FIGURE 5: Clinically significant deviations in contralateral $(\mathrm{Q} / \mathrm{Q} ; \mathrm{H} / \mathrm{H})$ ratios.

Figure 6 indicates the "distance" the right extensors must go to be within one SD of the permissible difference: in patient TB the right quadriceps exhibit $54 \%$ of left quadriceps torque and should be over $86 \%$ as strong to be within acceptable ranges of difference.

\section{Rehabilitative Implications}

The above profile implies a need to strengthen the right knee extensor mechanism at a rate twice that at which the right flexor mechanism is strengthened (See Figure 6).

The intervention goal is to increment strength as follows using the normative Standard Score Chart:

Right quadriceps, by $46 \mathrm{Nm}$ to $117 \mathrm{Nm}$; Right hamstrings, by 21 $\mathrm{Nm}$ to $66 \mathrm{Nm}$; Left hamstrings by $12 \mathrm{Nm}$ to $72 \mathrm{Nm}$; Left quadriceps to remain essentially unaltered.

The aim should be to increment strength at relative ratios of RQ: RH: $\mathbf{L H}=4: 2: 1$, per unit time. This would, in due course, result in a balanced achievement of average strength values, acceptably normal contralateral asymmetry (Q:Q; H:H) levels and normal ipsilateral (H/Q left; H/Q right) agonist/antagonist asymmetry ratios.

\section{Case Number Two}

Subject AB (Female): Bilateral Knee Surgery, 48 months previously.

\section{Presenting Asymmetries}

This subject has exceedingly weak knee extensors and very weak flexors and also has stronger left quadriceps and right hamstrings.

Figure 4 highlights the motor impairment of this subject, in which the left $H / Q$ ratio is an acceptable 0,67 , while the right $H / Q$ ratio is 1.09 (stronger flexors than extensors).

What should be a 1.0 Q:Q ratio is in fact 1.47 , but the $\mathrm{H}: \mathrm{H}$ ratio is normal, even though both hamstring groups rate "poor" in absolute strength (Figure 5).

\section{Rehabilitative Implications}

Clearly subject $\mathrm{AB}$ has about the same "distance" to go to bring right quadriceps and left hamstrings to within an acceptable approximation of their contralateral counterparts (Figure 6).

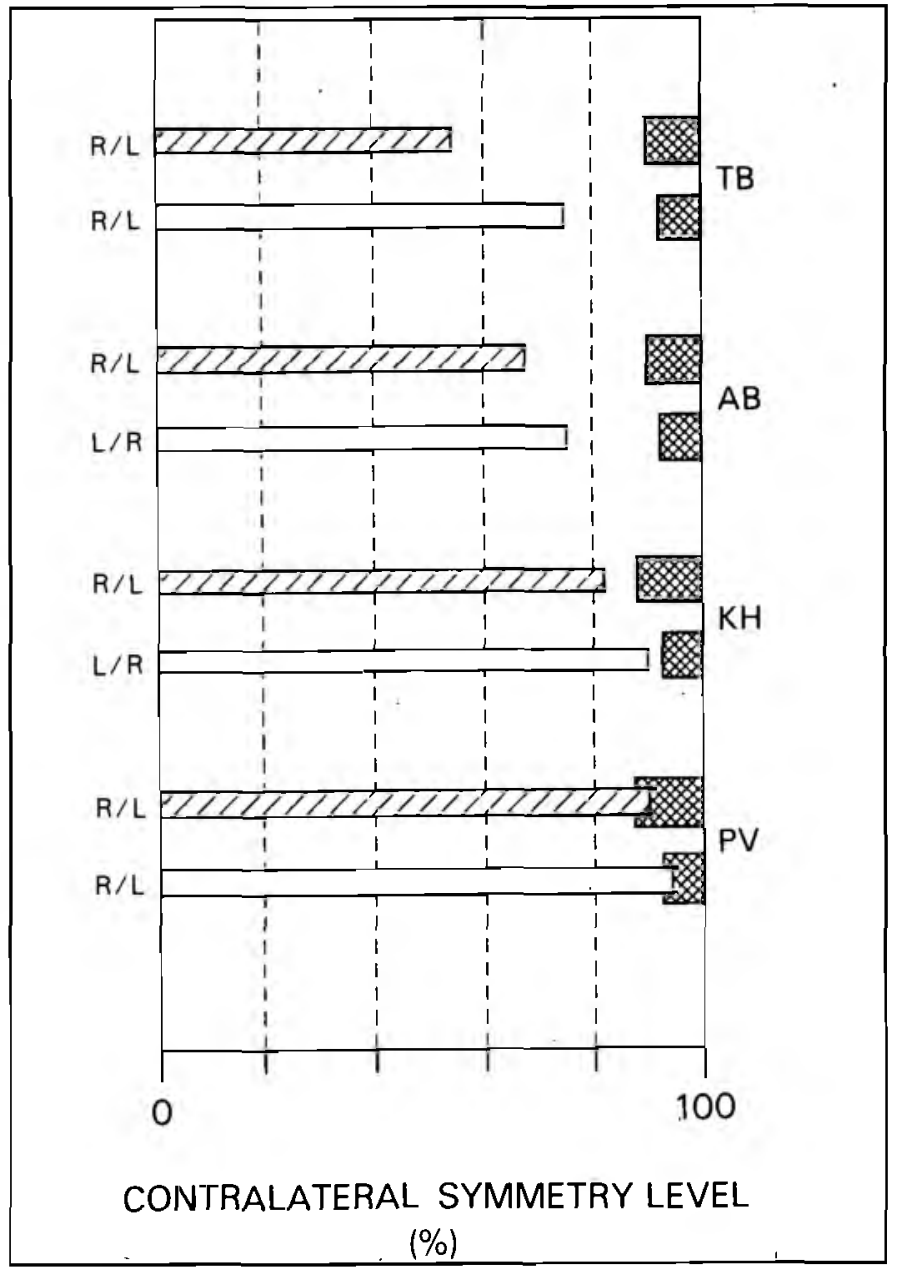

FIGURE 6: Clinically significant defects of the weaker knee, in percent of the stronger in selected cases.

shaded bas depicts weaker quadriceps, in percent of stronger. Open bar depicts wavkor hamstrings. Permissible deviations (le. normal asymmetry levels) ase indicated by soltd blocks on right. Width of gaps indicates extent of abnormal asymmetry. The rehablita the god is to close these gaps.

This should take precedence in the attempt to lift the absolute strength values on both sides to more acceptable levels. Using the normative Standard Score Chart (Table IV) the intervention goal is as follows:

RQ : LQ : LH : RH = $2: 1.5: 1: 1$, per unit time

\section{Case Number Three}

Subject KH (Male): Arthroscopic Meniscectory (R), 24 months previously.

\section{Presenting Asymmetries}

Here is a case in which, following meniscectomy $(R)$ the $Q: Q$ ratio, which should be 1.0 , is too high at 1.21 , the affected knee not having regained as much extensor strength as would be optimal. Consistent with this relatively reduced right knee extensor strength, (even though in absolute values it is "average"), the right flexor strength is too great for an optimal balance. Figure 4 shows a right $\mathrm{H} / \mathrm{Q}$ ratio two SD higher than the mean for seated isometric torques, and a left $H / Q$ ratio that is normal.

In this subject, as in the previous two, a distinct imbalance exists between left and right $\mathrm{H} / \mathrm{Q}$ ratios $(0.52 \mathrm{vs} 0.71)$. While this difference is nowhere near as great as that in the case of subject $A B$, it does show that, even though the score is "average" to "good" on all strength tests, there still exists a risk-increasing imbalance in $\mathrm{H} / \mathrm{O}$ ratios between the two limbs.

\section{Rehabilitative Implications}

This subject should concentrate on incrementing strength in the kniee extensors to raise their strength by almost $20 \%$ on each side. 


\section{Case Number Four}

Subject PV (Male): Arthroscopy for Patello-femoral Pathology (R), 36 months previously.

\section{Asymmetry Analysis}

In this case the strength score is "below average" in knee extension (X SS 43) and "poor" in knee flexions (X SS 34) bilaterally. As the subject is left-dominant for both extensors and flexors, the standard scores suggest similar H/Q ratios, which in fact is the case (see Figure 4). These ratios are about 0.47 which is one standard deviation below the normal seated isometric mean. As Figure 5 attests, $\mathrm{Q} / \mathrm{Q}$ and $\mathrm{H} / \mathrm{H}$ ratios are within normal limits, and Figure 6 shows that the weaker (R) knee is within acceptable levels of difference from values in the stronger limb.

Therefore there are no asymmetries of concern in this case, and whatever conditioning is needed to ensure optimal performance is restricted to a need to maintain these balances while simultaneously increasing left and right extensor and flexor strength. The suggested regimen is one which produces a $10 \%$ increment in strength of the quadriceps and a $25 \%$ increment in strength of the hamstrings (ie. a $\mathrm{Q}: \mathrm{H}=1: 2.5$ training ratio).

\section{Acknowledgement}

The meticulous contribution of Heidi Calitz during the data collection phase of this project is gratefully recognised.

\section{References}

1. Nunn KD, Mayhew JL. Comparison of three methods of assessing strength imbalances at the knee. Joumal of Orthopaedic and Sports Physical Therapy 1988;10(4):134-137.

2. Charteris J, Goslin BR. The Effects of position and movement velocity on isokinetic force output at the knee. Joumal of Sports Medicine and Physical Fitness 1982;22(2):154-160.

3. Levinrad I. The quadriceps-hamstring ratio. SA Runner/Tri-cycling March 1991.

4. Nosse JL Assessment of selected reports on the strength relationship. Journal of Orthopaedic and Sports Physical Therapy 1982;5:7885.

5. Hageman PA, Gillaspie DM, Hill LD. Effects of speed and limb dominance on eccentric and concentric isokinetic testing of the knee. Journal of Orhopaedic and Sports Physical Therapy 1988;10(2):59-65.

6. Klopfer DA, Greij SD. Examining quadriceps/hamstrings performance of high velocity isokinetics in untrained subjects. Joumal of $O r$ thopaedic and Sport Physical Therapy 1988;10(1):18-22.

7. Thompson Mc, Shingleton PT, Kegerreis ST. Comparison of values generated during testing of the knee using the Cybex II Plus and Biodex Model B-2000 isokinetic dynamometers. Journal of Orthopaedic and Sports Physical Therapy 1989;11(3):108-115.

8. Worrell TW, Denegar CR, Armstrong SLet al. Effect of body position on hamstring muscle group average torque. Joumal of Orhhopaedic and Sports Physical Therapy 1990;11(10):449454.

9. Charteris J, Goslin BR. In vivo approximations of the classic in vitro length-tension relationship: an isokinetic evaluation. Journal of Orthopaedic and Sports Physical Therapy 1986;7(5):222-231.
WORK IN THE USA

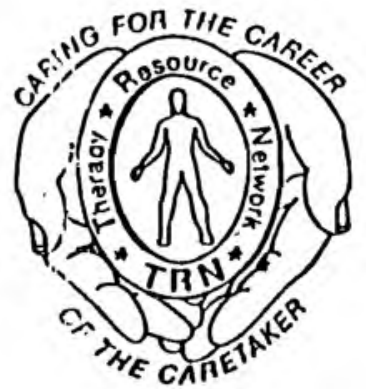

PHYSITHERAPISTS

\section{EXCELLENT JOBS}

We handle all licensure and visa paperwork.

Minimum commitment of one year required.

TRN fees paid by employer.

\section{Therapy Resource Network, Inc.}

P.O. Box 5430

199 North Main Street

Plymouth, Michigan, 48170

Call: 091-313 455-6660

\section{New! Reduce your treatment time drastically with the new cluster head applicators!}

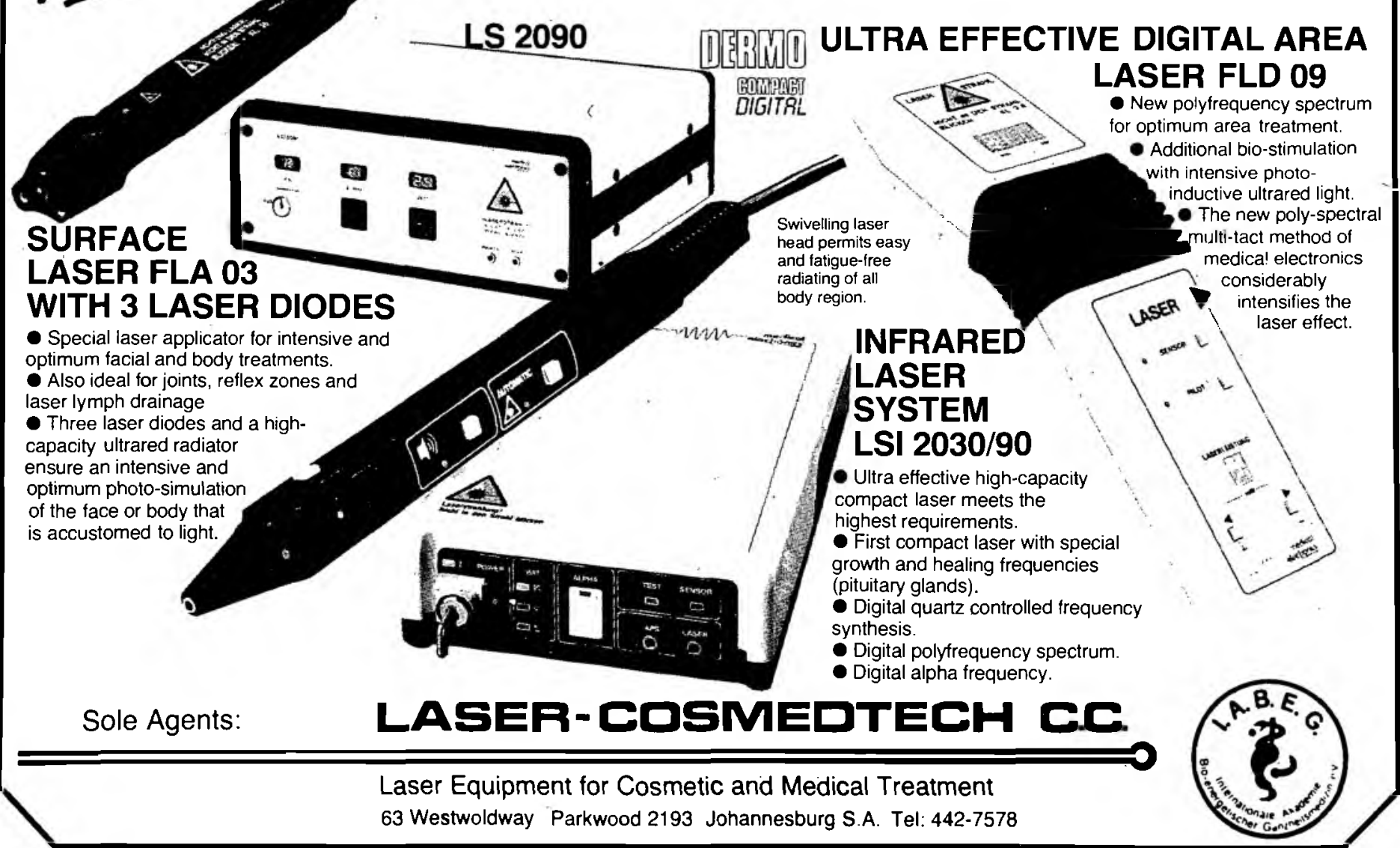

